\title{
ILOKUSI KOMUNIKATIF DALAM NOVEL THE PERFECT WORLD OF MIWAKO SUMIDA KARYA CLARISSA GOENAWAN
}

\author{
Marfiani Heryanto ${ }^{1}$, Misbah Priagung Nursalim ${ }^{2}$ \\ marfiani.heryanto@gmail.com¹, dosen00942@unpam.ac.id ${ }^{2}$ \\ Universitas Pamulang ${ }^{12}$
}

\begin{abstract}
ABSTRAK
Penelitian ini bertujuan untuk (1) mendeskripsikan jenis Ilokusi Komunikatif dalam Novel The Perfect World of Miwako Sumida karya Clarissa Goenawan (2) mendeskripsikan fungsi Ilokusi komunikatif dalam Novel The Perfect World of Miwako Sumida karya Clarissa Goenawan. Penelitian ini menggunakan metode desktiptif kualitatif. Berdasarkan analisis data, ditemukan sebanyak 47 data ilokusi komunikatif dan terdapat empat jenis ilokusi komunikatif. (1) jenis ilokusi komunikatif yang terdapat pada penelitian ini sebanyak 21 data ilokusi konstatif, ilokusi direktif sebanyak 11 data, ilokusi komisif sebanyak 7 data dan ilokusi acknowledgement sebanyak 8 data. (2) mendeskripsikan fungsi ilokusi komunikatif sebanyak 2 data ilokusi konstatif prediktif, konstatif retrodiktif sebanyak 1 data, konstatif deskriptif sebanyak 2 data, konstatif informatif sebanyak 2 data, konstatif konfirmatif sebanyak 2 data, konstatif konsesif terdapat 1 data, konstatif retraktif terdapat 1 data, konstatif dissentif sebanyak 2 data, konstatif disputatif sebanyak 2 data, konstatif sugestif sebanyak 5 data, dan konstatif suppositif terdapat 1 data. Fungsi ilokusi terdapat 1 data direktif requestive, direktif question sebanyak 5 data, direktif requirements terdapat 1 data, direktif prohibitives terdapat 1 data, direktif permissive terdapat 1 data, direktif advisories sebanyak 2 data. Fungsi ilokusi komisif sebanyak 2 data promises contract, komisif offer volunteer sebanyak 4 data, dan terdapat 1 data komisif offer bid. Fungsi ilokusi acknowledgement sebanyak 3 data acknowledgement apologize, ilokusi acknowledgement codole terdapat 1 data ilokusi acknowledgement congratulate terdapat 1 data, ilokusi acknowledgement greet sebanyak 2 data dan terdapat 1 data ilokusi acknowledgement thank.
\end{abstract}

Kata Kunci: Tindak tutur, ilokusi, ilokusi komunikatif.

\section{PENDAHULUAN}

Masyarakat dan bahasa merupakan hal yang tidak dapat dipisahkan dalam kehidupan sosial satu sama lainnya. Masyarakat sebagai pencipta bahasa, mampu menciptakan sebuah interaksi komunikasi. Tidak jarang dalam proses komunikasi terjadi kesalahan tuturan antara penutur dan mitra tutur. Kajian linguistik yang fokus dalam menjelaskan tindak tutur dan segala yang terjadi dalam proses tuturan tersebut adalah ilmu pragmatik. Pragmatik merupakan cabang ilmu linguistik yang mempelajari bahasa dan konteks. Pengertian bahasa sebagai alat komunikasi manusia untuk berinteraksi dalam sehari-hari. Sedangkan konteks merupakan situasi yang berdampingan dengan bahasa.

Pragmatik merupakan studi tentang makna yang disampaikan oleh penutur (penulis) dan ditafsirkan oleh pendengar (pembaca). Studi ini banyak berhubungan dengan analisis tentang apa yang dimaksudkan seseorang dengan tuturan-tuturannya daripada dengan makna terpisah dari kata dan frasa yang digunakan tuturan itu sendiri. Pragmatik adalah studi tentang maksud penutur (Yule, 2018 : 3). Carnap (dalam Suhartono, 2014 : 1.5) seorang filosof dan ahli logika menjelaskan bahwa pragmatik mempelajari konsepkonsep abstrak tertentu yang menunjuk pada agens. Dengan perkataan lain, pragmatik mempelajari hubungan konsep, yang merupakan tanda, dengan pemakai tanda tersebut. Dari pendapat tersebut dapat disimpulkan bahwa pragmatik merupakan ilmu yang mempelajari makna dari tindak tutur dengan melihat penafsiran mitra tutur terhadap tuturan dari penuturnya.

Banyak cabang di dalam ilmu pragmatik, dari tindak tutur, implikatur, deiksis dan juga kesantunan. Tindak tutur adalah hal pertama yang dijelaskan dalam ilmu pragmatik, karena ilmu ini adalah yang perlu dikuasai terlebih dahulu sebelum membahas ilmu-ilmu lainnya. Tindak tutur memiliki pengertian gejala 
individual, bersifat psikologis, dan keberlangsungannya ditentukan oleh kemampuan bahasa si penutur dalam menghadapi situasi tertentu (Chaer dan Agustina, $2010: 50$ ).

Novel merupakan salah satu karya sastra yang berisikan kisah dari kehidupan manusia. Melalui tulisan novel tersebut penulis memberikan pesan tersembunyi kepada pembaca berupa gambaran-gambaran realita kehidupan melalui cerita novel tersebut. Berdasarkan ulasan tersebut penulis ingin menganalisis tuturan-tuturan yang ada dalam novel tersebut. Dalam novel dengan berbagai tuturan antar tokoh tentu akan terjadi kesalahfahaman antara penutur dan mitra tutur.

Kesalahfahaman dalam tuturan salah satu yang dibahas dalam tindak tutur, banyak dalam percakapan di dalam novel yang mengambarkan tindak tutur baik disadari ataupun tidak oleh penulisnya. Tindak tutur dan kesalahfahaman di dalamnya merupakan hal yang menarik untuk dikaji dalam penelitian ilmiah. Berbagai konteks yang terdapat dalam sebuah tuturan akan menjawab bagaimana kesalahfahaman dapat terjadi. Salah satu karya yang menurut layak untuk dikaji dalam tindak tutur adalah novel The Perfect World of Miwako Sumida karya Clarissa Goenawan.

Clarissa Goenawan merupakan seorang novelis muda yang inspiratif. karyanya terkenal di Singapura. Usianya masih belia, dia mendapatkan banyak penghargaan di bidang sastra. Rainbird merupakan novel perdananya yang telah diterbitkan ke dalam sebelas bahasa. The Perfect World of Miwako Sumida merupakan novel yang diterbitkan pada bulan 10 Maret 2020. Novel ini berkisah tentang misteri kematian seorang mahasiswi Jepang, Miwako Sumida. Ryusei, temannya dari Universitas Waseda, mencari fakta atas kematian Miwako, ke sebuah desa, tempat terakhir yang dikunjungi Miwako. Clarissa dengan novelnya mampu membawa cerita cinta remaja yang dipandang sebagai karya yang kurang mendapatkan apresiasi oleh sastrawan, menjadi menarik dengan pemilihan diksi dan cara penceritaanya yang berbeda dengan novel remaja pada umumnya. Ini terbukti dari penghargaan yang ia dapatkan dari karyanya.

Novel ini menceritakan Ryusei penasaran dengan kematian dari Miwako, dalam perjalanannya mengungkap kematian dari Miwako tentu banyak tindak tutur yang dapat difahami ataupun tidak, dari tuturan antar tokoh di dalam novel ini. Salah satunya seperti saat Jin yang menagih janji kepada Toshi ditraktir di acara goukon. Dalam kutipannya tindak tutur yang terjadi adalah tindak tutur ilokusi konstatif berfungsi prediktif. Ilokusi Konstatif merupakan kepercayaan mengekspresian kepercayaan, bersamaan dengan pengekspresian maksud sehingga mitra tutur membentuk, meneruskan untuk memegang, kepercayaan yang sejenis (Ibrahim, 1993 : 21). Dalam kutipan ini Jin telah tahu jawaban yang akan diberikan Toshi saat ia menggodanya tentang masalah wanita yang diundang ke acara goukon. Jawaban yang diberikan oleh Toshi adalah menenangkan situasi, tetapi karena Jin telah tahu Toshi seseorang yang tenang dia pun menggoda kembali Toshi dengan traktiran yang dijanjikannya dengan apapun hasil yang akan mereka dapatkan nanti.

Tindak tutur ilokusi konstatif yang berfungsi predikif hanyalah sebagian dari empat jenis ilokusi menurut Ibrahim. Di dalam teorinya ia membagi ilokusi ke dalam empat bagian yaitu iloksi konstatif, ilokusi direktif, ilokusi komisif dan juga ilokusi acknowledgement (Ibrahim, 1993 : 14). Teori dari ibrahim ini yang 
akan penulis gunakan untuk menganalisis tindak tutur ilokusi dalam Novel The Perfect World of Miwako Sumida.

Ryusei adalah seorang mahasiswa yang berkuliah di Universitas Waseda, Jepang. Pertemuan pertama Ryusei dengan Miwako pada saat Goukon yang diadakan Toshi. Pertemuan pertama tersebut langsung membuat Ryusei jatuh cinta. Miwako sendiri merupakan salah satu dari tiga gadis yang berjanjian dengan Toshi di acara goukon. Secara kebetulan Miwako adalah teman satu SMA Jin. Miwako meruapakan gadis yang berparas serius dengan rambut hitam panjang teruntai, ia juga memakai kacamata bingkai tebal bermodel lama. Ryusei dengan Miwako sama sama memiliki kepribadian yang lebih diam, dalam acara yang di adakan Toshi pun Ryusei dan Miwako hanya menjadi pelengkap teman-temannya. Namun keindahan cerita Ryusei dengan Miwako tidak berlangsung lama setahun setelah pertemuan pertama di acara goukon, Miwako meninggal menyisakan misteri yang ingin diselidiki oleh Ryusei dan teman-temannya.

Dari uraian di atas, penelitian yang berjudul Ilokusi Komunikatif dalam Novel The Perfect World Of Miwako Sumida Karya Clarissa Goenawan penulis akan menganalisis tentang jenis tindak tutur dan juga fungsi ilokusi yang terdapat dalam novel The Perfect World Of Miwako Sumida Karya Clarissa Goenawan. Alasan penulis memilih judul ini karena dalam penyampaian tuturan yang dituliskan seperti novel, terkadang memiliki pemaknaan (respon) berbeda, melalui kajian ilokusi ini akan dijelaskan konteks sebenarnya tuturan tersebut dibuat pengarang berdasarkan pendekatan pragmatik. Konteks tuturan yang dipakai oleh penulis dalam penelitian ini adalah tuturan ilokusi. Sebuah tuturan memiliki fungsi menjelaskan sesuatu sekaligus memerintah dengan harapan lawan tutur merespon dari ucapan penutur. Teori ilokusi yang dikemukanan Prof. Dr. Abdul Syukur Ibrahim menjadi teori yang dipilih penulis untuk menganalisis tuturan-tuturan yang ada di dalam novel The Perfect World Of Miwako Sumida, ilokusi tersebut yaitu ilokusi konstatif, ilokusi direktif, ilokusi komisif dan ilokusi acknowledgment serta fungsi dari keempat jenis ilokusi tersebut. Harapan besar saat penulis melakukan penelitian ini ialah mampu memberikan wawasan berbeda dalam menganalisis novel dengan pendekatan yang jarang dipakai dalam sebuah analisis tindak tutur ilokusi khususnya di lingkungan Sastra Indonesia Universitas Pamulang

\section{TEORI DAN METODOLOGI}

Ibrahim (1993: 304) menjelaskan bahwa lokusi merupakan tindakan mengatakan sesuatu dan makna yang penutur katakan. Rustono (dalam Kurniawan, 2013: 13) menjelaskan bahwa lokusi adalah tindak tutur yang dimaksudkan untuk menyatakan sesuatu. Maksudnya, lokusi merupakan tindak tutur yang diujarkan dengan suatu makna atau acuan tertentu. Wijana dan Rohmadi (2018: 21) menjelaskan bahwa lokusi adalah tindak tutur menyatakan sesuatu itu disebut sebagai The Act of saying something. Yule (2018: 83) menjelaskan tindak lokusi adalah tindak dasar tuturan atau menghasilkan suatu ungkapan linguistik yang bermakna. Sementara Nadar (2013: 14) berpendapat lokusi adalah tindak tutur yang semata-mata menyatakan sesuatu, biasanya dipandang kurang penting dalam kajian tindak tutur. Sementara Austin (dalam Leech, 2011:316) menyatakan bahwa tindak tutur lokusi adalah melakukan tindakan mengatakan sesuatu. Menurut Prahastiwi tindak ilokusi merupakan tindak tutur yang mengandung maksud dan fungsi atau daya tutur (2018:134). 


\section{TEMUAN DAN PEMBAHASAN}

\section{Jenis Ilokusi Komunikatif}

a. Ilokusi Kontatif

\section{Data 01}

“Apapun hasilnya, kau sudah janji mentraktir kami. Kita tunggu lima menit lagi sebelum mulai memesan makanan."

"Diamlah" (Goenawan, 2020:10)

Kutipan tersebut terdapat tindak tutur ilokusi konstatif. Percakapan Jin dan Toshi terjadi karena adanya kepercayaan Jin (penutur) terhadap Toshi (mitra tutur) yang tetap akan mentraktir dia walau apapun hasilnya. Kepercayaan ini tercipta karena Jin tahu, Toshi merupakan teman yang sudah saling mengenal karakter. Kepercayaan yang ditunjukan Jin kepada Toshi membuatnya sadar ataupun tidak, Toshi menerima kepercayaan darinya untuk mentraktir makan. Jawaban yang diucapkan Toshi pun merupakan persetujuan atas kepercayaan yang diberikan Jin. Selanjutnya, pada kutipan berikutnya ditunjukan tentang ilokusi konstatif berupa :

\section{b. Ilokusi Direktif}

\section{Data 22}

"Kau yakin cewek-cewek itu tidak menolak kita?" Jin menggoda Toshi."

"Jangan bilang begitu. Mereka cuma terlambat." Toshi mnegetuk-ngetuk jari ke meja. "Sebentar lagi pasti datang."

"Apapun hasilnya, kau sudah janji mentraktir kami. Kita tunggu lima menit lagi sebelum mulai memesan makanan."

(Goenawan, 2020 :10).

Kutipan tersebut terdapat percakapan antara Jin dengan Thosi. Jin (penutur) menggoda Thosi dengan menanyakan tentang perempuan yang diundang mereka pasti menolak bertemu dengan mereka. Tuturan tersebut sebenarnya kode agar Thosi (mitra tutur) segera memesan makanan. Karena Jin beranggapan bahwa sudah terlalu lama mereka menunggu perempuan-perempuan yang diundang Toshi di acara Goukon nya, maka tuturan tersebut dikategorikan sebagai ilokusi direktif. Hal itu karena Jin bertanya kepada Toshi sebagai kode agar cepat memesan makanan. Kalimat tersebut dapat dikategorikan sebagai perintah dengan cara tidak langsung. Selanjutnya, kutipan ilokusi direktif ditunjukan pada kutipan berikut :

\section{c. Ilokusi Komisif}

\section{Data 33}


"Nah, Nona pekerja keras, sudah ketemu pekerjaan yang kau inginkan?"

Dia menggeleng. "Ada beberapa peluang dekat apartemenku, tapi upah per jamnya terlalu rendah. Aku berharap bisa dibayar lebih tinggi, soalnya aku benar-benar perlu menabung."

"Kau mau kuperkenalkan dengan bos di tempat kerja paruh waktuku? Pekerjaannya cukup banyak untuk kita berdua."

“Aku baru tahu kau bekerja paruh waktu," ucapnya. "Pekerjaan seperti apa?"

"Tidak terlalu sulit. Hanya bantu-bantu. Aku yakin kau pasti bisa."

"Dan berapa bayarannya untuk 'hanya bantu-bantu'?”

Aku mendekat dan membisikkan jumlahnya.

“Sebanyak itu?" ucapnya, sedikit terlalu keras.”(Goenawan, 2020:24)

Kutipan di atas merupakan percakapan Ryusei dan Miwako. Tuturan tersebut dikategorikan sebagai ilokusi komisif. Hal itu karena Ryusei (penutur) menawarkan pekerjaan yang dapat diambil oleh Miwako (mitra tutur) yang memerlukan untuk tambahan penghasilan. Ryusei mengajak mitra tuturnya terlibat pada tindakan yang akan dilakukannya nanti. Bertemu dengan bosnya dan menawarkan pekerjaan kepada Miwako karena imbalan yang di dapatkan sesuai bahkan lebih maka Miwako menerima tawaran Ryusei.

\section{d. Ilokusi Acknowledgement}

\section{Data 40}

"Aku ingin minta maaf," ucap Miwako setelah kami meninggalkan toko. "Kusangka kau hanya mengarang... soal ingin datang ke toko tadi."

Aku tertawa. "Kok bisa begitu? Memangnya tampangku seperti tidak membaca?"

"Ya," Miwako seketika menjawab. "Bagiku kau terlihat agak tolol." (Goenawan, 2020 : 17)

Kutipan di atas merupakan percakapan Miwako dan Ryusei. Tuturan ini dikategorikan sebagai ilokusi acknowledgement. Hal itu karena Miwako mengekpresikan permintaan maafnya karena menganggap Ryusei bukan tipe orang yang senang membaca dan datang ke toko buku. Respon Ryusei hanya tertawa mendengar permintaan maaf dari Miwako. Selanjutnya, kutipan ilokusi acknowledgement ditunjukan pada kutipan berikut :

\section{Fungsi Ilokusi Komunikatif}

a. Fungsi Konstatif

1) Tindak tutur konstatif prediktif

\section{Data 01}


“Apapun hasilnya, kau sudah janji mentraktir kami. Kita tunggu lima menit lagi sebelum mulai memesan makanan."

"Diamlah" (Goenawan, 2020:10)

Kutipan tersebut merupakan tindak tutur ilokusi konstatif yang berfungsi prediktif. Fungsi ini ditunjukan dari percakapan Jin dan Toshi terjadi karena adanya kepercayaan Jin (penutur) terhadap Toshi (mitra tutur) yang tetap akan mentraktir dia walau apapun hasilnya. Kepercayaan ini tercipta karena Jin tahu, Toshi merupakan teman yang sudah saling mengenal karakter. Jin dalam tuturan ini memprediksi tentang kehadiran para gadis yang diundang oleh Toshi seperti yang terlihat pada kutipan "Apapun hasilnya, kau sudah janji mentraktir kami. Kita tunggu lima menit lagi sebelum mulai memesan makanan.". Konsekuensi yang akan terjadi jika prediksi Jin tepat ialah Thosi harus mentraktir. Jin secara tidak langsung dalam tuturannya telah menentukan hasil dari peristiwa yang belum terjadi. Selanjutnya, kutipan ilokusi konstatif prediktif ditunjukan pada kutipan berikut :

\section{Data 02}

“Aku tidak mengira kau datang, Sumida," Ucapnya.

Si gadis berkacamata tersenyum tipis." Aku juga tidak.

Tidak kukira bakal melihatmu lagi. Aku heran kau bahkan masih ingat namaku." (Goenawan, $2020: 11)$

Kutipan di atas terdapat percakapan Jin dan Miwako. Keduanya melakukan percakapan tentang keterkejutan mereka yang bisa bertemu kembali di acara Toshi. Tuturan itu dapat dikategorikan ke dalam ilokusi konstatif prediktif yang berfungsi memprediksi. Hal itu karena Jin (penutur) dan Miwako (mitra tutur) percaya bahwa mereka tidak akan bertemu di acara yang dianggap oleh Jin bertolak belakang dengan kepribadian Miwako yang pendiam. Jin merasa terkejut karena merasa prediksinya Miwako tidak ikut acara yang diadakan Thosi seperti yang ditunukan pada kutipan Tidak kukira bakal melihatmu lagi. Aku heran kau bahkan masih ingat namaku.". Tetapi kenyataanya Miwako datang bersama teman-temannya dan ia pun (Jin) mengira tidak akan bertemu dengan Miwako lagi.

\section{2) Tindak tutur konstatif retrodiktif}

\section{Data 03}

“Tama hilang," ucapnya lirih. "Dia masih ada saat aku meninggalkan apartemen. Tapi, saat aku pulang, dia sudah tidak ada. Aku tidak tahu harus bagaimana."

"Aku terdiam sebentar, memcerna kabar itu. "Masuk dulu, Miwako." 
Setelah membimbingnya ke dalam, aku menarik kursi plastik. Miwako duduk, badannya gemetar. Aku pergi ke kantor untuk mengambil air hangat. Dia menerimanya, tetapi hanya memegangi gelas itu.

“Kau baik-baik saja?’Tanyaku, berjongkok di depannya.

Miwako menatapku. Setelah beberapa waktu dia bergumam, "Ya.”(Goenawan, 2020:104)

Kutipan di atas terdapat percakapan Ryusei dan Miwako. Tuturan tersebut dapat dikategorikan sebagai ilokusi konstatif dengan fungsi retrodiktif, hal itu karena Miwako (penutur) melaporkan kepada Ryusei bahwa Tama (kucing peliharaan) hilang seperti yang ditunjukan pada kutipan "Tama hilang," ucapnya lirih. "Dia masih ada saat aku meninggalkan apartemen. Tapi, saat aku pulang, dia sudah tidak ada. Aku tidak tahu harus bagaimana.”. Miwako percaya bahwa Ryusei dapat membantu dengan bercerita kepadanya. Ryusei (mitra tutur) percaya bahwa Miwako sedang bersedih Ryusei mengajaknya masuk dan duduk untu menenngkan diri, sambil memberikan air hangat.

\section{3) Tindak tutur konstatif deskriptif}

\section{Data 04}

"Pacarmu cantik sekali," dia melanjutkan. "Bukan imgin kurang ajar, tapi sepertinya dia lebih tua darimu, kan?"

"Memang. Dia baru saja berulang tahun ke-29."

Miwako mengangkat satu alis.

“Aku suka perempuan yang lebih tua. Mereka lebih berpengalaman. (Goenawan, 2020:23)

Kutipan di atas terdapat percakapan Miwako dan Ryusei. Tuturan ini dikategorikan sebagai ilokusi konstatif dengan fungsi deskriptif. Hal itu karena adanya penjelasan dari Ryusei tentang perempuan yang ditanyakan Miwako seperti yang ditunjukan pada kutipan "Pacarmu cantik sekali," dia melanjutkan. "Bukan imgin kurang ajar, tapi sepertinya dia lebih tua darimu, kan?" "Memang. Dia baru saja berulang tahun ke-29.”. Ryusei menjelaskan bahwa dia adalah laki-laki yang menyukai perempuan yang lebih tua karena baginya perempuan yang lebih tua sudah berpengalaman. Walaupun sebenarnya hal yang dilakukan Ryusei hanya sekadar candaan.

\section{4) Tindak tutur konstatif informatif}

\section{Data 06}

“Kau boleh memanggilku Fumi-nee,” ujar kakakku.

"Aku kakaknya Ryu dan pemilik Studio Garam. Selamat datang di kantorku."

Mata Miwako melebar. "Oh ya?" 
“Studio Garam,” ucap kakakku. "Kedengaran aneh, ya?”

"Bukan, bukan itu. Hanya... Ryusei bilang kau pacarnya."

Kakakku seketika terbahak-bahak. "Aku, pacarnya? Kau pasti bercanda. Aku tidak tertarik pada cowok yang baru saja puber.” (Goenawan, 2020:28)

Kutipan di atas merupakan percakapan Fumi-nee dan Miwako. Tuturan ini dikategorikan sebagai ilokusi konstatif dengan fungsi informatif yaitu tuturan ilokusi yang berisi informasi dari penutur dengan lawan tutur. Hal ini karena Fumi-nee (penutur) memberikan informasi bahwa dirinya adalah kakak dari Ryusei seperti yang ditunjukan pada kutipan "Aku kakaknya Ryu dan pemilik Studio Garam. Selamat datang di kantorku." . Fumi-nee pun menginformasikan tentang studio garamnya dan terakhir memberikan informasi bahwa ia tidak suka dengan laki-laki yang umurnya dibawah dia untuk menjawab Miwako yang mengira bahwa Fumi-nee adalah pacar Ryusei.

\section{b. Fungsi Ilokusi Direktif \\ 1) Tindak tutur direktif requestive}

\section{Data 22}

Aku menarik napas dalam-dalam dan memikirkan kalimat yang berkali-kali ku latih setiap kali kali tidak bisa tidur di malam hari. Kata-kata pun meluncur keluar.

"Aku suka padamu,"

Dia mengernyit.

"Aku ingin kita pacaran," Kataku cepat-cepat. "Kau mau?"

Dia diam saja, meski wajahnya merona merah. Setidaknya itu lebih baik daripada dia tidak bereaksi apa-apa. Akhirnya Miwako berkata,"itu tidak lucu."

Aku menelan ludah keras-keras. "Aku memang tidak bercanda."

Dia berdiri. "Cukup Ryusei. Kau sudah keleawatan."

"Miwako, aku serius. Kau tahu itu."

Tubuhnya tegang. Aku tahu mestinya aku berhenti, tetapi tidak bisa.

"Setidaknya cobalah dulu.” Lanjutku.

"tidak, ucapnya tegas. "Sudah ku bilang, hubungan kita tidak akan berhasil." (Goenawan, 2020:46)

Kutipan di atas terdapat percakapan antara Ryusei dan Miwako. Tuturan ini dikategorikan sebagai ilokusi direktif requestive yaitu mengekspresikan permintaan si penutur mengharapkan kepatuhan mitra tutur. Hal itu karena Ryusei meminta Miwako (mitra tutur) menerimanya menjadi pacar seperti yang terdapat pada kutipan "Aku ingin kita pacaran," Kataku cepat-cepat. "Kau mau?" 
Tetapi tindakan Miwako tidak berubah, ia tetap pada keputusannya untuk tidak menerima Ryusei. Miwako merasa hungunnya dengan Ryusei tidak akan berhasil.

\section{2) Tindak tutur direktif question}

Data 23

"Kau yakin cewek-cewek itu tidak menolak kita?" Jin menggoda Toshi."

"Jangan bilang begitu. Mereka cuma terlambat." Toshi mnegetuk-ngetuk jari ke meja. "Sebentar lagi pasti datang."

“Apapun hasilnya, kau sudah janji mentraktir kami. Kita tunggu lima menit lagi sebelum mulai memesan makanan.”

(Goenawan, $2020: 10)$.

Kutipan di atas terdapat percakapan Jin dan Thosi. Tuturan ini dikategorikan sebagai ilokusi direktif question yang fungsinya bertanya dengan maksud si mitra tutur melakukan sesuatu. Hal itu karena Jin (penutur) bertanya pada Thosi (mitra tutur) tentang para gadis yang diundang toshi mungkin akan menolak mereka karena para gadis yang diundang belum datang seperti yang terdapat pada kutipan "Kau yakin cewek-cewek itu tidak menolak kita?" Jin menggoda Toshi." Sebenarnya pertanyaan Jin sekadar basa-basi agar Toshi segera memesan makanan.

\section{3) Tindak tutur direktif requirements}

\section{Data 028 :}

Sekitar satu tahun lalu, kakakku perlu mendokumentasikan sebagian lukisannya. Aku sedang tidur-tiduran di kamar ketika dia masuk dan memberikan intruksi.

"Potret saja semua lukisan yang ada di studio." Dia mengulurkan sebuah kamera Nikon FM2.

"Tidak perlu bagus-bagus amat. Yang penting potretlah setiap karya seni. Minta bantuan Miwako."

"Untuk apa fotonya?"

"Untuk pameran," sahut kakakku. "Panitianya meminta foto-foto untuk katalog." (Goenawan, 2020:97)

Kutipan di atas merupakan percakapan Fumi-nee dan Ryusei. Tuturan ini dikategorikan sebagai ilokusi direktif Requirements berfungsi memberikan intruksi atau perintah dari penutur sebagai alasan si mitra tutur melakukan sesuatu. Hal itu karena Fumi-nee (penutur) memerintahkan adiknya Ryusei (mitra tutur) untuk memotret lukisannya dan Ryusei menanyakan alasannya seperti yang terlihat pada kutipan“Potret saja semua lukisan yang ada di studio.” Dia mengulurkan sebuah 
kamera Nikon FM2. "Tidak perlu bagus-bagus amat. Yang penting potretlah setiap karya seni. Minta bantuan Miwako.”. Fumi-nee menjawab fotonya akan dibuat untuk katalog pameran lukisan.

4) Tindak tutur direktif prohibitives

\section{Data 29}

Miwako berhenti di depan salah satu kotak kardus, lalu berjongkok dan membukanya. Ada seekor anak kucing di dalamnya. Bulunya putih bercak hitam dan oranye basah kuyup. Hewan mungil itu tampak kedinginan dan ketakutan.

"Jangan sentuh," ucapku. "Kau hanya akan menambah masalah, karena tidak mungkin membawanya pulang"

Mengabaikan nasihatku, Miwako mengangkat anak kucing itu. Hewan ini mendengkur dan meringkuk dalam pelukannya.

"Jangan cemas. Aku akan merawatnya," dia berkata.

Dia pasti bercanda. "Memangnya boleh memelihara kucing diapartemen?"

Tidak perlu ada yang tahu." (Goenawan, 2020:81)

Kutipan di atas merupakan percakapan Ryusei dan Miwako. Tuturan ini dikategorikan sebagai ilokusi direktif prohibitives berfungsi larangan dari penutur agar mitra tutur tidak melakukan sesuatu yang menurut penutur kurang baik bagi mitra tutur. Ryusei melarang Miwako untuk menyentuh anak kucing yang mereka temukan di jalan karena menurut Ryusei hal tersebut akan menambah masalah bagi Miwako seperti yang terlihat pada kutipan "Jangan sentuh,” ucapku. "Kau hanya akan menambah masalah, karena tidak mungkin membawanya pulang”. tetapi Miwako tetap akan membawa anak kucing ke apartemnnya.

\section{5) Tindak tutur direktif permissive}

\section{Data 30}

"Kalau kau tidak nyaman aku tinggal di sini, aku akan kembali ke gudang. Lebih baik begitu, kan? Aku bisa tidur di lantainya. Aku janji tak akan menyentuh barang-barangmu."

Tidak, itu tidak akan mungkin. Lantai beton studio sangat dingin dan keras, siapa pun bakal jatuh sakit jika bermalam di sana. Dia tahu salah besar membiarkan Eiji bermalam di apartemennya, dan dia hampir bisa mendengar suara Ryusei yang memarahinya, tetapi...

“Kalau kau capek kenapa kau masih berdiri di pintu?” Akhirnya Fumi berkata.

Mata Eiji berbinar. Aku boleh tinggal di sini?"

"Hanya untuk beberapa hari," ucap Fumi, terlalu cepat. "Sampai kau dapat pekerjaan dan menemukan akomondasi yang layak." (Goenawan, 2020 : 246- 247) 
Kutipan di atas terdapat percakapan antara Fumi-nee dan Eiji. Tuturan ini dikategorikan sebagai ilokusi direktif permissive berfungsi penutur mengizinkan bagi mitra tutur melakukan sesuatu secara bebas. Hal itu karena Fumi-nee mengizinkan Eiji tinggal sementara di apartemen Fumi-nee sampai ia memiliki pekerjaan dan akomodasi yang layak seperti yang terlihat pada kutipan "Hanya untuk beberapa hari," ucap Fumi, terlalu cepat. "Sampai kau dapat pekerjaan dan menemukan akomondasi yang layak.".

\section{6) Tindak tutur direktif advisories}

\section{Data 31}

Fumio menaruh sapu, lalu berlari ke dalam. Ibunya sedang berjalan kearahnya, membawa kotak hadiah.

“Berapa kali harus ku bilang supaya berjalan pelan-pelan dengan tenang di koridor?" Ucap ibunya dengan dahi berkerut. "Ini kuil kau bisa mengganggu pengunjung."

“Tak ada pengunjung sepagi ini," protes Fumio.

Ibunya mendelik padanya. "Sebagai putra pendeta, kau harus menjaga kelakuan. Suatu hari kelak, kau akan mewarisi kuil ini dari ayahmu." (Goenawan, 2020 : 302)

Kutipan di atas merupakan percakapan antara ibu Fumio dan Fumio. Tuturan ini dikategorikan sebagai ilokusi direktif advisories berfungsi nasihat dari penutur untuk mitra tutur agar mitra tutur mengikuti nasihatnya. Hal itu karena Ibu (penutur) menasihati Fumio (mitra tutur) agar berjalan pelan-pelan saat dikuil dengan alasan akan mengganggu pengunjung yang datang tetapi Fumio membantah dengan alasan tidak ada pengunjung yang datang sepagi itu seperti yang trelihat pada kutipan "Berapa kali harus ku bilang supaya berjalan pelan-pelan dengan tenang di koridor?" Ucap ibunya dengan dahi berkerut. "Ini kuil kau bisa mengganggu pengunjung.". Nasihat tersebut dimaksudkan agar suatu saat nanti Fumio menjaga kuil keluarganya karena ia adalah keturunan dari pendeta akan mewarisi kuil tersebut dari ayahnya

\section{c. Fungsi Ilokusi Komisif}

\section{1) Tindak tutur komisif promises contract}

Data 33

"Saya akan datang," kataku. "Pukul berapa sebaiknya?"

"Kalau pukul lima bagaimana?

"Tidak masalah." Aku mengambil bolpoin dan notes Fumi-nee yang selalu tersedia di sebelah telepon. "Boleh saya minta alamat Anda?" 
Aku menulis yang didiktekan ibu Miwako. Rumahnya terletak di Katsushika. Paling tidak butuh waktu sejam ke sana, mungkin lebih. (Goenawan, 2020:89)

Kutipan di atas terdapat percakapan Ryusei dan Ibu Miwako. Tuturan ini dikategorikan sebagai ilokusi komisif promises (contract) berfungsi menjanjikan atau menyepakati suatu tindakan penutur dan mitra tutur. Hal itu karena kesepakatan yang dilakukan Ryusei (penutur) dan Ibu Miwako (mitra tutur) adalah bertemu untuk membahas tentang kematian Miwako di Katsushika pada pukul lima seperti yang terdapat pada kutipan "Kalau pukul lima bagaimana? Dan "Tidak masalah.” Aku mengambil bolpoin dan notes Fumi-nee yang selalu tersedia di sebelah telepon. "Boleh saya minta alamat Anda?"

\section{2) Tindak tutur komisif offers Volunteer}

\section{Data 35}

"Sini, aku bantu," ucapku, mengambil kantong dari tangan Miwako dan nyaris menjatuhkannya.

"Wow, kau beli apa? Berat betul."

"Cuma bir."

Wajahnya tersenyum lebar. "Ya, pesta untuk satu orang. Karena semester baru akan dimulai, kupikir sebaiknya kurayakan.”

"Aku ikut," kataku. "Dua orang selalu lebih baik daripada sendirian dalam urusan minumminum." (Goenawan, 2020:67)

Kutipan di atas merupakan percakapan Ryusei dan Miwako. Tuturan ini dikategorikan sebagai ilokusi komisif offers volunteer. Berfungsi menawarkan sebuah tindakan yang akan dilakukan tanpa meminta imbalan. Hal itu karena Ryusei (penutur) menawarkan bantuan untuk membawakan kantong belanjaan Miwako yang ternyata bir untuk merayakan pergantian semester seperti yang terdapat pada kutipan "Sini, aku bantu," ucapku, mengambil kantong dari tangan Miwako dan nyaris menjatuhkannya. Dan Ryusei pun menawarkan diri ikut dalam pesta yang dibuat Miwako karena dia beranggapan bahwa berdua lebih baik dari sendirian dalam urusan minum-minum.

\section{4) Fungsi ilokusi komisif offer bid}

\section{Data 38}

"Kau mau jadi murid ku? Sudah saatnya aku punya anak magang."

Mata Miwako melebar. "Kau serius?"

"Kau tidak mau?"

“Tentu saja mau," Katanya. "Tapi, apa tidak merepotkanmu?" 
“Aku tak bakal menawarkan ini kalau ternyata merepotkan," ucap Fumi, mengedipkan mata. "Masalahnya aku sangat keras. Kau harus bekerja mati-matian, dan aku serius soal itu." (Goenawan, $2020: 249)$

Kutipan di atas merupakan percakapan Fumi-nee dan Miwako. Tuturan dikategorikan sebagai ilokusi komisif offers volunteer berfungsi menawarkan sebuah tindakan yang akan dilakukan tanpa meminta imbalan. Hal itu karena Fumi-nee (penutur) menawarkan Miwako (mitra tutur) bekerja magang bersamanya, Miwako begitu gembira mendengar tawaran tersebut walau ia merasa akan merepotkan Fumi-nee seperti yang terlihat pada kutipam "Kau mau jadi murid ku? Sudah saatnya aku punya anak magang.”. Tetapi Fumi-nee merasa Miwako sudah layak untuk magang membantu dirinya membuat lukisan. Selanjutnya, kutipan ilokusi komisif offers bid ditunjukan pada kutipan berikut :

\section{d. Ilokusi Acknowledgement}

\section{1) Tindak tutur acknowledgement apologize}

\section{Data 40}

"Aku ingin minta maaf," ucap Miwako setelah kami meninggalkan toko. "Kusangka kau hanya mengarang... soal ingin datang ke toko tadi."

Aku tertawa. "Kok bisa begitu? Memangnya tampangku seperti tidak membaca?"

"Ya," Miwako seketika menjawab. "Bagiku kau terlihat agak tolol." (Goenawan, 2020 : 17).

Kutipan di atas merupakan percakapan Miwako dan Ryusei. Tuturan yang ini dikategorikan sebagai ilokusi acknowledgement apologize berfungsi penyesalan dari penutur disertai permintaan maaf dari terhadap mitra tutur. Hal itu karena Miwako (penutur) meminta maaf karena telah menganggap Ryusei (mitra tutur) tidak suka membaca dan datang ke toko buku seperti yang terdapat pada kutipan "Aku ingin minta maaf," ucap Miwako setelah kami meninggalkan toko. "Kusangka kau hanya mengarang... soal ingin datang ke toko tadi.". Ryusei hanya merespon dengan tertawa. Anggapan salah tersebut karena Miwako menganggap Ryusei sebagai orang yang tolol.

\section{2) Tindak tutur acknowledgement condole}

Data 43

"Kami tinggal di sini beberapa tahun," kakakku menjelaskan, memotek sumpitnya menjadi dua. Orangtua kami tewas dalam kecelakaan mobil."

“Maaf, aku tidak bermaksud mengungkitnya," Kata Miwako. 
"Jangan khawatir, kejadiannya sudah lama kok. Dan memang takdirnya begitu." Fumi-nee membuka kotak bentonya—ayam katsu dengan sayur favoritku. (Goenawan, 2020:33)

Kutipan di atas merupakan percakapan Miwako dan Fumi-nee. Tuturan ini dikategorikan sebagai ilokusi acknowledgement condole berfungsi penutur menyampaikan simpati kepada musibah yang di alami mitra tutur. Hal itu karena Miwako menyampaikan simpatinya saat Fumi-nee menceritakan tentang orangtuanya yang telah meninggal saat Fumi-nee dan Ryusei masih kecil seperti yang terdapat pada kutipan "Maaf, aku tidak bermaksud mengungkitnya," Kata Miwako. Fumine menganggap semua telah berlalu. Dia sudah mengikhlaskannya.

\section{3) Tindak tutur acknowledgement congratulate}

\section{Data 44}

Chie menarik napas dalam-dalam dan menyambar ransel. Perlahan, dia memegang tambang lusuh itu. Rasanya dingin saat disentuh, basah dengan uap dari kabut. Setiap papan kayu bergeser saat diinjak, dan celah antar papan tidak rata. Chie berusaha menghindari celah-celah tersebut, tetapi untuk itu mau tidak mau dia harus memandangi papan satu per satu, dengan jantung berdebar kenang. Saat dia hampir sampai di ujung jembatan, Ryusei mengulurkan tangan dan Chie menyambutnya dengan lega.

"Kau berhasil," kata Ryusei.

"Ya." Chie menghela napas dan mulai tertawa. "Ini gila. Apa sih yang kita lakukan di sini?"

(Goenawan, $2020: 159)$

Kutipan di atas merupakan percakapan antara Ryusei dan Chie. Tuturan ini dikategorikan sebagai ilokusi acknowledgement congratulate berfungsi mengekpresikan kebahagian dengan mengucapkan selamat terhadap mitra tutur. Ilokusi tersebut ditunjukan pada kutipan "Kau berhasil," kata Ryusei. Hal itu karena Ryusei mengucapkan selamat pada Chie yang telah berhasil melewati jembatan tua yang berbahaya Chie yang senang merasa tidak percaya dirinya mampu melewati jembatan tersebut.

\section{4) Tindak tutur acknowledgement greet}

\section{Data 45}

Aku mencoba tidak sempoyongan saat berjalan ke ruang duduk. Sambil berdeham, aku mengangkat telepon.

"Selamat pagi, ini Ryusei Yanagi." 
"Selamat pagi, Yanagi-san," seorang wanita dengan suara teredam menyambutku. "Ini Akemi Kojima, ibu Miwako. Kita sempat bertemu saat kau melayat."

Kojima. Bukannya itu nama Miwako sebelumnya?

"Yanagi-san?"

"Ya, maaf," aku cepat-cepat menyahut."Apa yang bisa saya bantu, Kojima-san?"

"Ini soal Miwako.” (Goenawan, 2020:88)

Kutipan di atas merupakan percakapan Ryusei dan Ibu Miwako. Tuturan ini dikategorikan sebagai ilokusi acknowledgement greet berfungsi ucapan salam dari penutur kepada mitra tutur sebagai bentuk kesopanan atau juga perasaan senang bertemu dengan mitra tutur. Hal itu karena Ibu Miwako mengucapkan salam kepada Ryusei dalam telepon sebagai bentuk kesopanannya yaitu pada kutipan "Selamat pagi, ini Ryusei Yanagi.". Sebelum ia memberitahukan maksud ia menelpon Ryusei. hal yang yang membuktikan ini sebagai salam ialah disebutkannya nama lengkap dari Ryusei Yanagi.

\section{5) Tindak tutur acknowledgement thank}

\section{Data 47}

“Terima kasih sudah menemaniku," ucapnya. "Nanti ku kabari jika Tama pulang."

Aku mengusap rambutnya dengan lembut. "Jangan terlalu memikirkan soal ini. Sebaiknya kau istirahat. "Aku yakin Tama segera kembali." (Goenawan, 2020:110)

Kutipan di atas merupakan percakapan Miwako dan Ryusei. Tuturan ini dikategorikan sebagai ilokusi acknowledgement thank berfungsi penutur mengucapkan terima kasih kepada mitra tutur karena mendapatkan bantuan. Hal itu karena Miwako (penutur) berterimakasih kepada Ryusei (mitra tutur) yang telah membantu Miwako mencari Tama yang hilang seperti yang terdpat pada kutipan "Terima kasih sudah menemaniku," ucapnya. "Nanti ku kabari jika Tama pulang." Miwako akan mengabari Ryusei jika ia pulang. Ryusei merespon menenangkan Miwako agar tidak terlalu memikirkan Tama dan menyuruh Miwako beristirahat. 


\section{KESIMPULAN}

Dalam analisis data ini, penulis menemukan jenis ilokusi konstatif dalam novel The Perfect World of Miwako Sumida karya Clarissa Goenawan sebanyak 21 data, Ilokusi direktif sebanyak 11 data Ilokusi komisif sebanyak 7 data dan Ilokusi acknowledgement sebanyak 8 data,Total data yang dianalisis dalam penelitian ini sebanyak 47 data. Selanjutnya, penulis menemukan fungsi ilokusi konstatif dalam novel The Perfect World of Miwako Sumida karya Clarissa Goenawan sebanyak 21data. Pertama sebanyak 2 data ilokusi konstatif prediktif, konstatif retrodiktif sebanyak 1data, konstatif deskriptif sebanyak 2 data, konstatif informatif sebanyak 2 data, konstatif konfirmatif sebanyak 2 data, konstatif konsesif terdapat 1 data, konstatif retraktif terdapat 1 data, konstatif dissentif sebanyak 2 data, konstatif disputatif sebanyak 2 data, konstatif sugestif sebanyak 5 data, konstatif suppositif terdapat 1 data. Kedua fungsi ilokusi direktif requestive terdapat 1 data, direktif question sebanyak 5 data, direktif requirements terdapat 1 data, direktif prohibitives terdapat 1 data, direktif permissive terdapat 1 data, direktif advisories sebanyak 2 data. Ketiga fungsi ilokusi komisif promises contract sebanyak 2 data, komisif offer volunter sebanyak 4 data, offer bid terdapat 1 data. Keempat, fungsi ilokusi acknowledgement apologize sebanyak 3 data, ilokusi acknowledgement codole terdapat 1 data, ilokusi acknowledgement congratulate terdapat 1 data, ilokusi acknowledgement greet sebanyak 2 data, ilokusi acknowledgement thank sebanyak 1 data.

\section{DAFTAR PUSTAKA}

Alwasilah, A. Chaedar. 2005. Pengantar Penelitian Linguistik Terapan. Jakarta : Pusat Bahasa Departemen Pendidikan Nasional.

Arief, Nur Fajar. 2015. Tindak Tutur Guru dalam Wacana Kelas. Modul. Malang : Worldwide Reader.

Chaer, Abdul dan Leonie Agustina. 2004. Sosiolinguistik. Jakarta : Rineka Cipta.

Goenawan, Clarissa. 2020. The Perfect World of Miwako Sumida. Jakarta : Gramedia Pustaka.

Ibrahim, Abdul Syukur. 1993. Kajian Tindak Tutur. Surabaya: Usaha Nasional.

Leech, Geoffrey. 2011. Prinsip-Prinsip Pragmatik. Depok : Univestitas Indonesia.

Moleong, Lexy J. 2014. Metodologi Penelitian Kualitatif. Bandung : Rosdakarya.

Nadar, F.X. 2018. Pragmatik dan Penelitian Pragmatik. Yogyakarta : Graha Ilmu.

Ritchi, Jane, and Jane Lewis. 2003. Qualitative Research Practice A Guide for Social Science Students and Researchers. London : SAGE Publications.

Sudaryanto. 2015. Metode dan Aneka Teknik Analisis Bahasa (Pengantar Penelitian Wahana Kebudayaan Secara Linguistis). Yogyakarta: Universitas Sanata Dharma.

Sudaryat, Dayat. 2006. Makna Dalam Wacana (Prinsip-Prinsip Semantik dan Pragmatik). Bandung : Yrama Widya.

Suhartono, dan Yuniseffendri. 2014. Pragmatik. Modul. Tangerang Selatan. Universitas Terbuka.

Wijana, I Dewa Putu dan Muhammad Rohmadi. 2018. Analisis Wacana Pragmatik Kajian Teori dan Analisis. Surakarta : Yuma Pustaka.

Yule, George. 2018. Pragmatik. Yogyakarta : Pustaka Pelajar.

Zaim, Muhammad. 2014. Metode Penelitian Bahasa (Pendekatan Struktural). Padang : FBS UNP Press.

Referensi Jurnal

Apriastuti, N. N. A. A. (2017). Bentuk, Fungsi, dan Jenis Tindak Tutur dalam Komunikasi Siswa di Kelas IX Unggulan SMP PGRI 3 Denpasar. Jurnal Ilmiah Pendidikan dan Pembelajaran.

Aroh dan Tri Pujiati. 2019. Tindak Tutur Komisif Dalam Pemilihan Calon Gubernur Dan Calon Wakil Gubernur Dki Pada Pemberitaan Media Online. Jurnal. Univesitas Pamulang.

Khalimah, Nur. 2016. Tindak Tutur Direktif Pada Dialog Film Cinta Suci Zahrana Sutradara Chaerul Umam, Relevansinya Sebagai Bahan Ajar Pembelajaran Menyimak Dan Berbicara, Dan Skenario Pembelajarannya Pada Siswa Kelas XI SMA. Skripsi. Universitas Muhammadiyah Purworejo.

Kurniawan, Fransiscus Xaverius Berti. 2013. Tindak Tutur Ilokusi Dalam Novel La Barka Karya N.H DINI. Universitas Sanata Dharma. 
Marsan, Silviana. 2018. Analisis Penggunaan Bahasa Pada Papan Iklan Di Kuala Lumpur (Kajian Sosiopragmatik). Jurnal. STKIP Insan Madani Air Molek.

Muchtar, Ahmad Zainul. 2017. Tindak Tutur Komisif Anime Haikyuu Episode 1-10 Karya Haruichi Furudate. Skripsi. Universitas Brawijaya

Murti, Aska Rizkia dan Zamzam Nurhuda. 2019. Tindak Tutur Direktif Dalam Novel Susah Sinyal Karya Ika Natasa dan Ernest Prakasa. Jurnal. Universitas Pamulang.

Nirmala, Vita. 2015. Tindak Tutur Ilokusi Pada Iklan Komersial Sumatera Ekspres. Jurnal. Palembang. Balai Bahasa Provinsi Sumatera Selatan.

Nores, Welly dkk. 2017. Analisis Tindak Tutur Pemasar Asuransi Kepada Nasabah Ditinjau Dari Perspektif Pragmatik. Jurnal. Bandung : Universitas Siliwangi.

Nugraha. 2019. Kualitas Terjemahan Tindak Tutur Ekspresif Dalam Novel Breaking Down (Awal Yang Baru) Karya Stephenie Meyer. Jurnal. Bandung: UIN Sunan Gunung Djati.

Pradana, Gilang dan Asep Purwo Yudi Utomo. 2020. Tindak Tutur Ilokusi Dalam Cuitan Akun Twitter Gubernur Jawa Tengah Ganjar Pranowo. Jurnal. Semarang : UNS.

Prahastiwi, Arunika Harum dkk. 2018. Tindak Tutur Ilokusi di Pondok Modern Selamat Kendal. Jurnal. Semarang. UNS.

Septiana, Lurida Zinta. 2014. Fungsi Tuturan Konstatif Pada Komik Petualangan Asterix "La Serpe D'or" Karya Renè Goscinny Dan Albert Uderzo. Skripsi.Yogyakarta. Universitas Yogyakarta.

Soecherman, Nadya Mustika Kansa. Tidak Tutur Ilokusi Antar Aministator E-Commerce Dengan Costumer Karenina Store. Jurnal. Universitas Pamulang.

Rahma, Anis Nurulita. 2014. Analisis Tindak Tutur Ilokusi Dalam Dialog Film Animasi Meraih Mimpi. Jurnal. Universitas Airlangga.

Umaroh, Liya dan Neni Kurniawati. 2020. Dominasi Ilokusi dan Perlokusi dalam Transaksi Jual Beli. Semarang : Universitas Dian Nuswantoro.

Widyawati, Neni dan Asep Purwo Yudi Utomo. 2020. Tindak Tutur Ilokusi dalam Video Podcast Deddy

Corbuzier dan Najwa Shihab pada Media Sosial Youtube. Jurnal. Semarang : Universitas Negeri Semarang. 